\title{
Application of Fuzzy Analytical Hierarchy Process (FAHP) for Selecting the Suitable Hydraulic Fracturing Method in Oil Recovery Enhancement
}

\author{
Mohammad Hossein Ahmadi ${ }^{1}$, Arash Ebrahimabadii ${ }^{2}$, Mohsen Aleali ${ }^{1}$, \\ Abolghasem Emamzadeh ${ }^{1}$ \\ ${ }^{I}$ Department of Petroleum Engineering, Science and Research Branch, Islamic Azad University, Tehran, Iran \\ ${ }^{2}$ Department of Mining, Qaemshahr Branch, Islamic Azad University, Qaemshahr, Iran
}

*Corresponding Author: Arash Ebrahimabadi, Department of Mining, Qaemshahr Branch, Islamic Azad University, Qaemshahr, Iran

\begin{abstract}
Hydraulic fracturing is one of the applicable methods for well stimulating to enhance oil recovery. Hydraulic fracturing operations are designed according to the parameters such as tectonic conditions of the area and the harnessing technology which was used. The present study was conducted to select the best hydraulic fracturing method in order to increase the oil recovery by using multi-criteria decision making methods; in respect of the way, fuzzyAnalytic Hierarchy Process (FAHP) is used to analyze the hydraulic fracturing techniquesin one of oilfields in Iran.Consequently, the results of analyses showed that Hydra-Jet Fracturingand Zipper Fracturingwith the scores of 0.150 and 0.149 are found as the most preferable methodologies, respectively. Since then, Hydraulic Fracturing with Foam-Based Fluids and Hydraulic Fracturing with Oil-Based Fluids in the third and fourth ranks. The last priorities are related to the Exothermic Hydraulic Fracturing and Hydraulic Fracturing with Acid-Based Fluids with the scores of 0.088 and 0.065 , respectively.
\end{abstract}

Keywords: Hydraulic Fracturing, FAHP, Oil Recovery Factor, Hydra-Jet Fracturing

\section{INTRODUCTION}

Hydraulic fracturing, commonly considered as the fracking, is an applicable technique which was used by the petroleum industries for several decades to drill hydrocarbons trapped deep under the surface; in respect of the way, the principles of this methodology are not recently utilized. Fracturing approach firstly established at the commercial level in the United States as early as 1947, and after that it considered as the preferable techniques in numerous countries such as Russia, Iran and Canada. By and large fracking was not an economically competitive process and had limited applications until the last decade. Several factors altered the importance of this technology which the affordability and the ubiquity use of recent innovation in the technological tools in the drilling and exploration industries especially in the well construction processes and the recovery of gas regarding the massive volume of natural gas sources worldwide. Thereby, this recent and harnessing technologies revolutionize the way petroleum industries drill oil and gas reservoirs along the coming decades [1-6].

However, reservoir characteristics and the wrong orientation in the design of the hydraulic fracturing operations make the fractures inefficient and they squander vast sums of money for operating the procedures. One of the primary ways of studying the created fractures is imaging logs such as FMI and FMS which are based on the electrical resistance of the formation, well fluid, and on the basis of sound waves [7-12]. The interpretation of these logs can determine the degree of opening, the length of the created fracture, the effect of initial fractures on the whole process and the direction of the fracture; in respect of the way, the operational accuracy will be examined. Hydraulic fracturing has taken place in many Iranian wells (over the past three decades), and now that fields are under development. Moreover, the FMI logs with high horizontal resolution provide a nearly complete picture of the well [3]. Among the significant factors which affecting the hydraulic fracturing, the following phenomena could be mentioned as the operational activities that needs to be done; 
Application of Fuzzy Analytical Hierarchy Process (FAHP) for Selecting the Suitable Hydraulic Fracturing Method in Oil Recovery Enhancement

- Choosing the appropriate fluid to create fracture and the preferable method of fracturing which has a very important effect on the efficiency of this operation and if these two factors are not corrected in accordance with the reservoir characteristics, the operation of the hydraulic fracturing would not have a significant effect on the production process of the reservoir. In addition, the fluid used to create the fracture is one of the most complex fluids made up of many materials; one of these is propane. Propane is a material made of various particles such as ceramic, and polymer glass. By creating a fracture in the layer, these materials are placed inside the slots to prevent them from closing.

- How to choose a well or the proper level for gutter operations; It may not be necessary to create a fracture in all wells in a reservoir and therefore, in order to economically save the selection of the well and the formation in which an artificial fracture is to be created. It has a high sensitivity.

- How the mechanical properties of the rock affect the gutting operations; rock properties must be fully determined so that during the formation of the fracture, no deterioration is created and the operation is successful.

- How the effects of artificial and natural fractures on each other; hence, their effects should be properly studied [6, 7-14].

An illustration of the basic hydraulic fracturing is schematically shown in figure 1. Moreover, a schematic of fracturing operations is shown in figure 2. For horizontal and vertical wells.

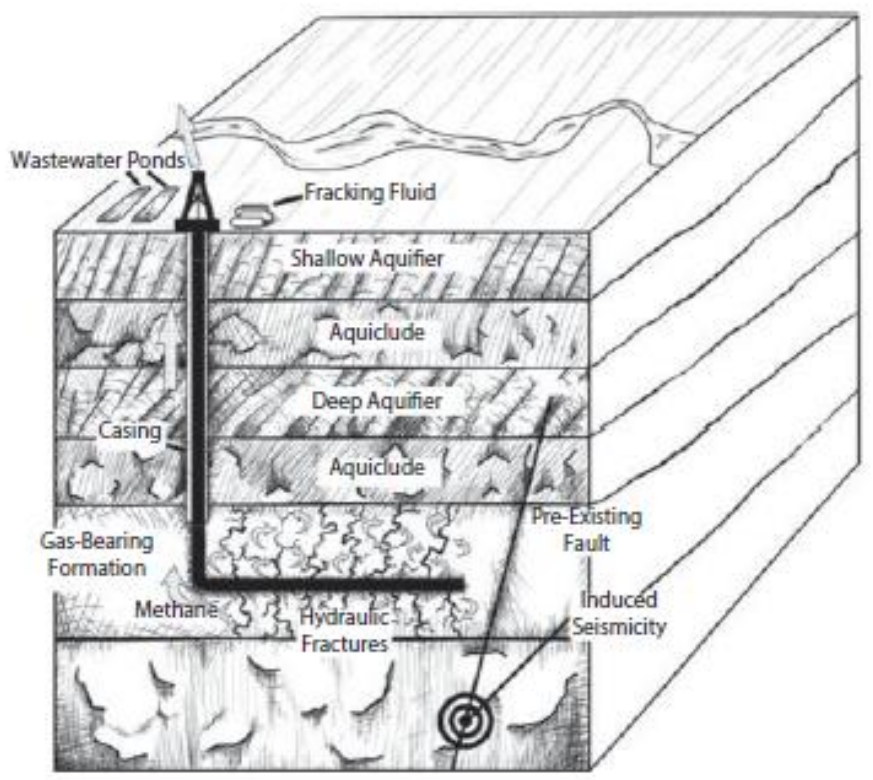

Figure1. Illustration of the basic fracturing process [6]

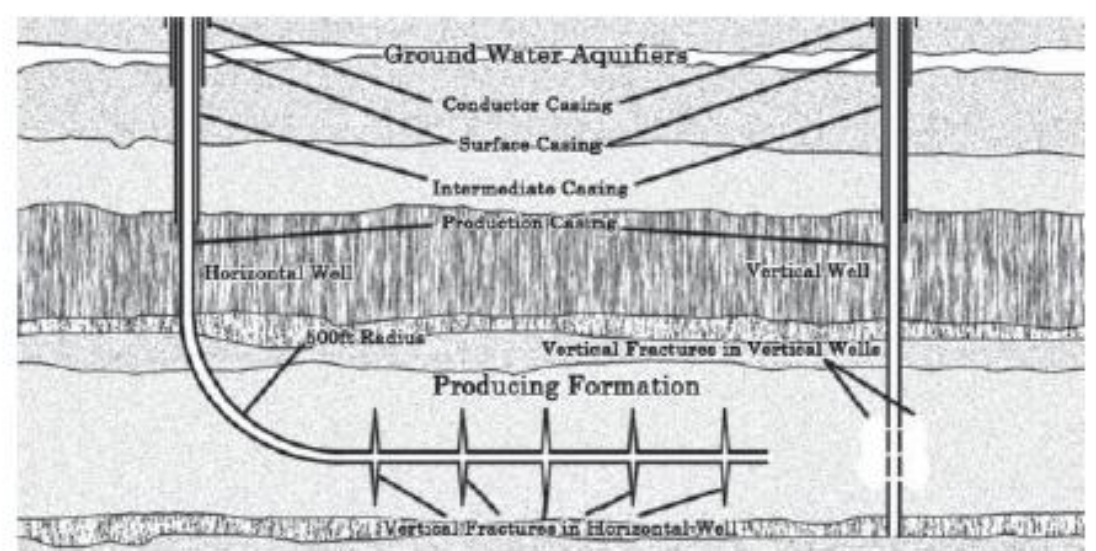

Figure2. Illustrates horizontal and vertical wells [6] 
Application of Fuzzy Analytical Hierarchy Process (FAHP) for Selecting the Suitable Hydraulic Fracturing Method in Oil Recovery Enhancement

Some interesting technologies have been recently developed. These are reviewed in the following[1517].

1- Zipper Fracturing

2- Hydra-jet fracturing

3- Exothermic Hydraulic Fracturing

4- Hydraulic Fracturing with Foam-based fluids

5- Hydraulic Fracturing with Oil-based fluids

6- Hydraulic Fracturing with Acid-based fluids

Deciding and choosing the best model involve expressing the objectives accurately, identifying the various possible solutions, evaluating their feasibility, evaluating the consequencesof implementing each solution, and finally selecting and implementing it. In most cases, decisions are desirable and with the consent of the decision maker, which has been decided on several criteria. Criteria may be quantitative or qualitative. In multi-criteria decision-making methods that have been respected by researchers in recent decades, a multi-criteria measure is used instead of an optimization measurement. Multi-criteria decision making models are divided into two main categories of multiobjective decision models (henceforth; MODM) and multi-criteria decision models (henceforth; MCDM). In general, MODM s are used to design and multi-index models to select the best option. The main difference between MODM models and MCDM models is that the former is defined in the continuous decision space and the latter is defined on the discrete decision space. In general, there are three things to be done about the criteria used in the issues [18-24]:

- Converting qualitative criteria into quantitative.

- Alter current criteria into the Non-Scale Criteria.

- Determine the relative weights of the criteria.

2. Methodology

\subsection{Decision Making Methods Procedure}

Generally, one of two following methodologies are available to implement a decision:

- Trial and error method

- Modeling method

In the test and error method, the decision maker confronts the reality by choosing one of the options and seeing the result, if the decision error is high and the problems occur, the decision would alter and other options might be chosen. On the contrary, in modeling, the decision maker models the real problem, identifies its elements and their impact on each other, and analyzes the model and predicts the performance of a real problem. In a general review, it is said that modeling is generally a process that requires a decent undergraduate work. The use of experts in modeling is necessary and, on the contrary, the following benefits are obtained;

- Cost and time savings

- Use in design

- Predicting the behavior and performance of the system

- Contribute to educational goals

\subsection{Fuzzy Hierarchical Analysis Method (FAHP)}

This method has provided a broad field for facilitating the decision-making process and is one of the most comprehensive systems designed for decision making with multiple criteria, since it enables the formulation of the problem to be hierarchical and possible to consider getting quantitative and qualitative criteria simultaneously. After introducing the Fuzzy AHP method by the year of the 1970s, many models have been presented by FAHP. In these methods, fuzzy and hierarchical concepts are 
Application of Fuzzy Analytical Hierarchy Process (FAHP) for Selecting the Suitable Hydraulic Fracturing Method in Oil Recovery Enhancement

used in combination. Given that the provision of verbs is verbally easier for decision makers than providing a response, it is important to use fuzzy concepts in decision making. Although the purpose of the hierarchical analysis method is to obtain the opinion of experts and experts, the method of hierarchical analysis of classics does not correctly reflect the way human thinking, because in pair wise comparisons of this method of numbers accurately used. Other cases that are often criticized for hierarchical analysis are the existence of an unbalanced scale in judgments, the uncertainty and inaccuracy of pair comparisons. Decision makers are often unable to express their opinion on excellence due to the fuzzy nature of pair comparisons. For this reason, in their judgments, they prefer to present an interval in place of a fixed number. In 1996, a method called the "Fuzzy Analytical Hierarchy Process" was developed by a Chinese researcher named Chang. The numbers used in this method are fuzzy triangular numbers.

\subsection{Gathering Data}

In this research, experts from the Global Petrochemical Company Kish have been interviewed to extract the factors affecting the outcome of hydraulic fracturing and, in fact, to find the appropriate criteria and options for research, as well as to complete the questionnaires of the multi-criteria decision making methodology. Global Petrotek Kish is an Iranian Oilfield Services Co., which operates in the field of drilling, logistics and drilling support, maintenance and repair consulting, engineering consultancy, and supply of materials.

\subsection{Method of Investigation}

One of the most important stages of the investigation is the gathering Information. The information needed to conduct the research can be collected in different ways. Various tools like observation, interviews, questionnaires, etc. are available to obtain data. Each of these tools has some disadvantages and advantages that should be taken into consideration when using them so that the validity of the research is not compromised and the strengths of the tool are strengthened. Each researcher should choose one or several tools according to the nature of the problem and, after obtaining the necessary conditions for the validity of these tools, use them to collect the data. The choice of tools should be such that the interrogator can defend his choice of instrument and thereby validate his research achievements.Decision-making criteria are demonstrated in table 1.

Table1. Making Decision Criterion

\begin{tabular}{|c|c|}
\hline Row & Decision-making criteria for Hydraulic Fracturing \\
\hline 1 & Existence of porous materials in the source rock \\
\hline 2 & Non-Linear Parameters like Rock characteristics \\
\hline 3 & Sidewall pressure \\
\hline 4 & Geometry of injected section \\
\hline 5 & Current discontinuity in the rock \\
\hline 6 & In-situ stresses and formation strain \\
\hline
\end{tabular}

\section{RESULTS AND DISCUSSION}

As can be seen in Table 2, in order to increase the hydraulic fracture to increase the recovery rate of oil, the Earth Strain with a weight of 0.306 was chosen as the best significant criteria among other Criterion. Since then, Sidewall pressure, Current discontinuity in the rock, and Non-Linear Parameters like Rock Expansion are in the sequential level of importance; 0.289, 0.162, and 0.120 respectively. Regarding the experts responding, Existence of porous materials in the source rock and Geometry of injected section are categorized as the least criterion.

Table2. Criteria normalized weights

\begin{tabular}{|l|c|}
\hline Decision-making Criteria for Hydraulic Fracturing & Criteria normalized weights \\
\hline Existence of porous materials in the source rock & 0.073 \\
\hline Non-Linear Parameters like Rock characteristics & 0.120 \\
\hline Sidewall pressure & 0.289 \\
\hline Geometry of injected section & 0.051 \\
\hline Current discontinuity in the rock & 0162 \\
\hline In-situ stresses and formation strain & 0.306 \\
\hline
\end{tabular}


Application of Fuzzy Analytical Hierarchy Process (FAHP) for Selecting the Suitable Hydraulic Fracturing Method in Oil Recovery Enhancement

As shown in Table 3, in order to increase the hydraulic fracture up to the FAHP analysis to increase the recovery rate of oil, the Zipper Fracturing and Hydra-jet fracturing with the weight of 0.150 and 0.149 respectively was chosen as the best method among other methods. After that, Exothermic Hydraulic Fracturing and Hydraulic Fracturing with Foam-based fluids with the normal weight of 0.109 and 0.104 are in the following ratings. The least preferred techniques are Hydraulic Fracturing with Oil-based fluids and Hydraulic Fracturing with Acid-based fluids with the weights of 0.088 and 0.065 respectively.

Table3. Hydraulic Fracturing Techniques rating according to the FAHP

\begin{tabular}{|l|c|c|}
\hline Hydraulic Fracturing Techniques & Normal Weight & Rating \\
\hline Zipper Fracturing & 0.150 & 1 \\
\hline Hydra-jet fracturing & 0.149 & 2 \\
\hline Exothermic Hydraulic Fracturing & 0.109 & 3 \\
\hline Hydraulic Fracturing with Foam-based fluids & 0.104 & 5 \\
\hline Hydraulic Fracturing with Oil-based fluids & 0.088 & 6 \\
\hline Hydraulic Fracturing with Acid-based fluids & 0.065 & \\
\hline
\end{tabular}

\section{Conclusion}

Hydraulic fracturing is one of the most preferable techniques for increasing the oil recovery factor and due to the comprehensive interviews among petroleum experts Zipper Fracturing and Hydra-jet fracturing with the weight of 0.150 and 0.149 are the most common. Next, Hydraulic Fracturing with Oil-based fluids and Hydraulic Fracturing with Acid-based fluids with the weights of 0.088 and 0.065 are the least preferable techniques in FAHP analysis. In addition, Earth Strain and Sidewall pressure with the weight of 0.306 and 0.289 are the best criterion on the selection of hydraulic fracturing techniques.

\section{REFERENCES}

[1] Cheremisinoff, N.P. and A. Davletshin, Hydraulic fracturing operations: Handbook of environmental management practices. 2015: John Wiley \& Sons.

[2] Zhang, Q., et al., Study of the effects of hydraulic fracturing at different dip angles for the development of coalbed methane: a case study in the southeast part of Qinshui Basin, China. International Journal of Oil, Gas and Coal Technology, 2017. 14(1-2): p. 186-200.

[3] Kunyun, T. and Z. Jiyu, The Application of Hydraulic Fracturing Outburst Prevention Measures. Procedia Engineering, 2011. 26(Supplement C): p. 495-500.

[4] Guo, J., et al., Numerical simulation of interaction of hydraulic fracture and natural fracture based on the cohesive zone finite element method. Journal of Natural Gas Science and Engineering, 2015. 25(Supplement C): p. 180-188.

[5] Li, Q., et al., A review on hydraulic fracturing of unconventional reservoir. Petroleum, 2015. 1(1): p. 8-15.

[6] Dahi Taleghani, A., M. Gonzalez, and A. Shojaei, Overview of numerical models for interactionsbetween hydraulic fractures and natural fractures: Challenges and limitations. Computers and Geotechnics, 2016. 71(Supplement C): p. 361-368.

[7] Davarpanah, A., M. Kakoli, and M. Ahmadi, Analysis of Fractured Reservoir Structure by Interpretation of FMI and VSP Logs. J Marine Sci Res Dev 6: 216. doi: 10.4172/2155-9910.1000216 Page 2 of 5 Volume 6•Issue 6•1000216. Receiver's correction, 2016.

[8] Zou, Y., et al., Numerical investigation of hydraulic fracture network propagation in naturally fractured shale formations. Journal of Structural Geology, 2016. 84(Supplement C): p. 1-13.

[9] Weng, X., Modeling of complex hydraulic fractures in naturally fractured formation. Journal of Unconventional Oil and Gas Resources, 2015. 9(Supplement C): p. 114-135.

[10] Osiptsov, A.A., Fluid Mechanics of Hydraulic Fracturing: a Review. Journal of Petroleum Science and Engineering, 2017. 156(Supplement C): p. 513-535.

[11] Mulliner, E., N. Malys, and V. Maliene, Comparative analysis of MCDM methods for the assessment of sustainable housing affordability. Omega, 2016. 59: p. 146-156.

[12] Rajasekaran, K., et al., A Review on Employing Multi Criteria Decision Making Methods for Supplier Selection. Asian Journal of Research in Social Sciences and Humanities, 2016. 6(6): p. 802-8.10

[13] Hsu, C.-H., A.-Y. Chang, and W. Luo, Identifying key performance factors for sustainability development of SMEs-integrating QFD and fuzzy MADM methods. Journal of Cleaner Production, 2017. 161: p. 629645 . 
Application of Fuzzy Analytical Hierarchy Process (FAHP) for Selecting the Suitable Hydraulic Fracturing Method in Oil Recovery Enhancement

[14] Yazdani, M., et al., Sensitivity analysis in MADM methods: application of material selection. Engineering Economics, 2016. 27(4): p. 382-391.

[15] Amini, M., S. Chang, and B. Malmir. A fuzzy MADM method for uncertain attributes using ranking distribution. in Proceedings of the Industrial andSystems Engineering Research Conference. 2016.

[16] Bakeshlou, E.A., et al., Evaluating a green supplier selection problem using a hybrid MODM algorithm. Journal of Intelligent Manufacturing, 2017. 28(4): p. 913-927.

[17] Charms, A., W. Cooper, and B. Golany, Relative Effects by Data Envelopment Analysis of Service Specific and Joint National Advertising in Navy Recruitment Activities. Center for Cybernetic Studies, The University of Texas at Austin, Austin, TX, 1986.

[18] Fan, G., et al., A hybrid fuzzy evaluation method for curtain grouting efficiency assessment based on an FAHP method extended by D numbers. Expert Systems with Applications, 2016. 44: p. 289-303.

[19] Saha, D., B.S. Roy, and P. Das. Anti-islanding detection method selection for grid connected DFIG wind farms using ANP method. in Power India International Conference (PIICON), 2016 IEEE 7th. 2016. IEEE.

[20] Jeong, J.S., A Spatial Regional Planning Assessment for Green Development Towards Ecotourism with Use of MCDA/SAW Method (Case Study: Spanish Rural Housings). Urban and Regional Planning, 2016. 1(4): p. 69.

[21] Qin, J., X. Liu, and W. Pedrycz, A multiple attribute interval type-2 fuzzy group decision making and its application to supplier selection with extended LINMAP method. Soft Computing, 2017. 21(12): p. 32073226.

[22] Amin, S.S. and M.N. Rajhans, Application of Integrated FAHP and FTOPSIS Method for Prioritization and Selection of Suppliers": Case Study in Automotive Industry. 2016.

[23] Yager, R.R. Crisp vs. Fuzzy Data in MulticriteriaDecision Making: The Case of the VIKOR Method. in Advances in Fuzzy Logic and Technology 2017: Proceedings of: EUSFLAT-2017-The 10th Conference of the European Society for Fuzzy Logic and Technology, September 11-15, 2017, Warsaw, Poland IWIFSGN'2017-TheSixteenth International Workshop on Intuitionistic Fuzzy Sets and Generalized Nets, September 13-15, 2017, Warsaw, Poland. 2017. Springer.

[24] Hashemi, S.S., et al., Multicriteria group decision making with ELECTRE III method based on intervalvalued intuitionistic fuzzy information. Applied Mathematical Modelling, 2016. 40(2): p. 1554-1564.

[25] Shukla, S., et al., An integrated decision making approach for ERP system selection using SWARA and PROMETHEE method. International Journal of Intelligent Enterprise, 2016. 3(2): p. 120-147.

\section{AUTHORS' BIOGRAPHY}

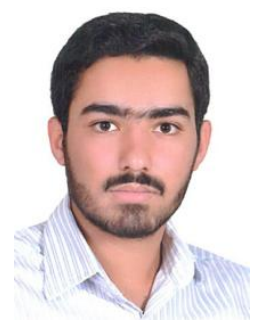

Mohammad Hossein Ahmadi, Master degree of Petroleum Engineering at Islamic Azad University, Tehran science and research Branch. My current interests in petroleum engineering sciences include a full-field study of Data Gathering, Reservoir Simulation, History Matching and Prediction. Furthermore, he concentrated more on the Multi-criteria decision making models on the oil recovery enhancement and suggested optimum solutions to choose the best Hydraulic Fracturing procedures.

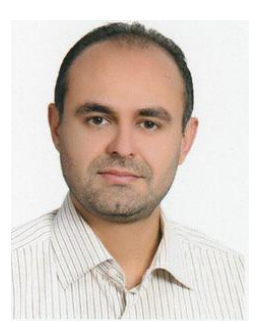

Dr. Arash Ebrahimabadi, is associate professor and M.SC. and doctoral student supervisor, and head of Department of Mining Engineering at Islamic Azad University, Qaemshahr Branch, Iran, where he specializes in interaction of mechanical miners and rock mass, engineering rock mechanics, mechanized tunneling and underground mining, rock cutting, petroleum Geomechanics and drilling. He cooperates (as part time) with Department of Petroleum Engineering, and Department of Mining Engineering at Azad University, Science and Research Branch, Tehran South Branch and Central Tehran Branch, Tehran, Iran. He managed several research projects for the office of vice chancellor for research and technology of Islamic Azad University, Qaemshahr Branch. He has served as mine supervisor and technical advisor in drilling operations for seven years. To date, Dr. Ebrahimabadi has published more than 70 papers and one book entitled "Roadheader's performance evaluation". He is a referee and member of scientific committee for Journal of Environmental Geology as well as head of scientific committee for Mine Sciences Conference (Iran). He is a member of Iranian Mining Engineering Organization (IMEO), Iranian Society of Mining Engineering (IRSME) and Iranian Society for Rock Mechanics (IRSRM). 
Application of Fuzzy Analytical Hierarchy Process (FAHP) for Selecting the Suitable Hydraulic Fracturing Method in Oil Recovery Enhancement



Dr. Mohsen Aleali, is associate professor and M.SC. and doctoral student supervisor, and Deputy of Petroleum Engineering Campus at Islamic Azad University, Tehran science and research Branch, where he specializes in geological engineering and operates such related projects in the university.

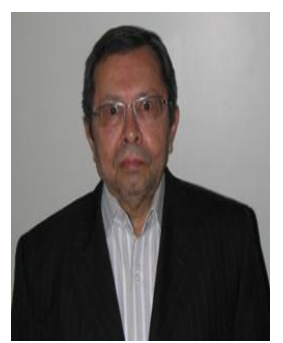

Dr. Abolghasem Emamzadeh, is associate professor and M.SC. and doctoral student supervisor, and Head of Petroleum Engineering Campus at Islamic Azad University, Tehran science and research Branch, where he specializes in mathematics and related analytical performances.

Citation: Arash Ebrahimabadi et al, (2018). Application of Fuzzy Analytical Hierarchy Process (FAHP) for Selecting the Suitable Hydraulic Fracturing Method in Oil Recovery Enhancement, International Journal of Petroleum and Petrochemical Engineering (IJPPE), 4(1), pp.1-7, DOI: http://dx.doi.org/10.20431/2454-7980. 0401001

Copyright: (C) 2018 Arash Ebrahimabadi. This is an open-access article distributed under the terms of the Creative Commons Attribution License, which permits unrestricted use, distribution, and reproduction in any medium, provided the original author and source are credited 